を用いて酸素と $\mathrm{d}-\mathrm{p} \pi$ 相互作用をする.この効果が大 きい元素は架橋結合エネルギーに比べて非架橋結合エネ ルギーがより大きいと思われる. アルカリイオン/網目 形成イオンの比が等しい $\mathrm{R}_{2} \mathrm{Si}_{2} \mathrm{O}_{5}, \mathrm{RPO}_{8}$ 及び $\mathrm{R}_{2} \mathrm{Ge}_{2} \mathrm{O}_{5}$ ガラスについて $E_{\mathrm{nb}} / E_{\mathrm{b}}$ 比を比較してみると $\mathrm{Ge}<\mathrm{Si}<$ $\mathrm{P}$ の順に大きいことが分る. $\mathrm{P}$ は d-p $\pi$ による二重結合を 持つことを考え合わせると $\mathrm{E}_{\mathrm{nb}} / \mathrm{E}_{\mathrm{b}} \sim 1.6$ となるのも不 思議ではない. $\mathrm{Ge}<\mathrm{Si}$ であるのは第 4 周期元素である $\mathrm{Ge}$ が第 3 周期元素である $\mathrm{Si}$ と比較して原子半径も大 きく酸素との軌道の重なりが小さいためと解釈できる.

\section{文献}

1）高橋克明，吉尾哲夫，䵫協，78，29-38 (1970).

2）高橋克明, 吉尾哲夫, 嗐協, 78, 329-37 (1970).

3）高橋克明, 吉尾哲夫, 窵協, 84, 62-70 (1976).

4）高橋克明, 吉尾哲夫, 丸岡幸一, 案協, 82, 193-201 (1974).

5）吉尾哲夫，高橋克明，窵協，83，575-81 (1975).

6) 高橋克明, 吉尾哲夫, 窯協, 85, 65-73 (1977).

7) 高橋克明, 尾坂明義, 林 聡, 窵協, 90, 8-13 (1982).

8）高橋克明, 尾坂明義, 林 聡, 㸃協, 90, 51-55 (1982).

9) JANAF Thermochemical Tables, US Department of Commerce, a) 2nd ed. (1971); b) 1974-Suppl.; c) 1975-Suppl.; d) 1978-Suppl.

10) L. Pauling, "The Nature of the Chemical Bond", 3rd ed., Chap. 3-5, Cornell University Press, New York (1960) p. 83.

11) K.-H. Sun, J. Am. Ceram. Soc., 30, 277-81 (1947).

12) S.S. Wise, J.L. Margrave, H.F. Feder and W.N. Hubbard, J. Phys. Chem., 67, 815-21 (1963).

13) C. Hummel and H.E. Schweite, Glatechn. Ber., 32,
327-35, 413-20 (1959).

14) P. Gross, C. Haymann and H.T. Bingham, Trans. Faraday Soc., 62, 2388-94 (1966).

15) R.J.L. Andon and K.C. Mills, J. Chem. Thermodymamics. 3, 583-87 (1971).

16) a) J.C. Southard, J. Am. Chem. Soc., 63, 3147-50 (1941).

b) G.K. Johnson and W.N. Hubbard, J. Chem. Thermodynamics, 1, 459-68 (1969).

17) Cited by O. Kubachewski and C.B. Alcock in "Metallurgical Thermochemistry", 5th ed., Pergamon Press, New York (1979).

18) S. Cantor, J. Chem. Phys., 59, 5189-94 (1973).

19) C.E. Moore, "Atomic Energy Levels", Vol. III, NBS Circ. No. 467 (1949), cited in "Kagaku-Binran" (Handbook for Chemists), Chemical Society of Japan, Maruzen, Tokyo (1975).

20) J.H.E. Jeffes and A.E.M. Warners, JCS Faraday I, 71, 670-73 (1975)

21) J. Krogh-Moe, Acta Cryst., B 30, 578-82 (1974).

22) J. Krogh-Moe, ibid., B 24, 179-81 (1968).

23) J. Krogh-Moe, ibid., B 28, 3089-93 (1972).

24) A. Osaka and K. Takahashi, Yogyo-Kyokai-Shi, 91, 374-77 (1983).

25) R.D. Shannon and C.T. Prewitt, Acta Cryst., B 25, 925-46 (1969).

26) Crystal structures reported in Acta Crystallographica; a) $\mathrm{Li}_{2} \mathrm{Si}_{2} \mathrm{O}_{5}: 14,389$ (1961), b) $\mathrm{Li}_{2} \mathrm{SiO}_{3}: 9,251$ (1956), c) $\alpha-\mathrm{Na}_{2} \mathrm{Si}_{2} \mathrm{O}_{5}: \mathbf{B} 24,13(1968)$, d) $\beta^{-}$ $\mathrm{Na}_{2} \mathrm{Si}_{2} \mathrm{O}_{5}:$ B 24, 1077 (1968), e) $\mathrm{Na}_{2} \mathrm{SiO}_{3}: 22,37$ (1967), f) $\mathrm{NaPO}_{8}: 14,844$ (1961), 16, 640 (1963), g) $\mathrm{K}_{2} \mathrm{Si}_{4} \mathrm{O}_{9}: \mathbf{B} 30,2206(1974)$, h) $\mathrm{K}_{2} \mathrm{~B}_{4} \mathrm{O}_{7}:$ B 28, 3089 (1972), i) $\mathrm{KPO}_{8}: 16,623$ (1963).

27) R.W. Wycoff, "Crystal Structures", 2nd ed., Vol. 1, Chap. IV, a.1. Interscience, New York (1960).

論 文・Paper

\title{
MO- $\mathrm{P}_{2} \mathrm{O}_{5}$ 系の熱化学的挙動及び $\mathrm{M}\left(\mathrm{PO}_{3}\right)_{2}$ ガラスの 結合エネルギー関係について
}

\author{
尾 坂 明 義・高 橋 克 明 \\ (岡山大学 工学部、工業化学科)
}

\begin{abstract}
$\mathrm{MO}-\mathrm{P}_{2} \mathrm{O}_{5}$ 系ガラス及び結晶 $(\mathrm{M}=\mathrm{Mg}, \mathrm{Ca}, \mathrm{Sr})$ の $3 \mathrm{~N} \mathrm{HNO}_{3}$ 水溶液中への溶解熱 と組成との 関係を $\mathrm{P}-\mathrm{O}^{\mathrm{b}}$ 架橋結合解離熱の立場加組成領域 $0<\mathrm{MO}+\mathrm{H}_{2} \mathrm{O} / \mathrm{P}_{2} \mathrm{O}_{5}(=r)<1, \quad 1<r<2$, $2<r<3$ において検討した. 溶解熱より計算される $\mathrm{M}\left(\mathrm{PO}_{8}\right)_{2}$ ガラスの生成熱を用いて，アルカ リリン酸塩ガラスにおけると同様に $E(\mathrm{P}=\mathrm{O}) / E\left(\mathrm{P}-\mathrm{O}^{\mathrm{b}}\right)=1.75$ 及び 2.0 と仮定して, $\mathrm{P}-\mathrm{O}$ 架橋結 合, 非架橋結合エネルギー $\left(E\left(\mathrm{P}-\mathrm{O}^{\mathrm{b}}\right), E\left(\mathrm{P}-\mathrm{O}^{\mathrm{nb}}\right)\right)$ 並びに $\mathrm{O}-\mathrm{M}-\mathrm{O}$ 結合エネルギー $E(\mathrm{OM})$ を求 めた.




\title{
Heats of Solution of the Glasses and Crystals in the Systems MO- $\mathrm{P}_{2} \mathrm{O}_{5}$ and Bond Energy Relations in $\mathbf{M}\left(\mathrm{PO}_{3}\right)_{2}$ Glasses
}

\author{
Akiyoshi OSAKA and Katsuaki TAKAHASHI \\ $\left(\begin{array}{l}\text { Department of Industrial Chemistry, School of Engineering, } \\ \text { Okayama University } \\ \text { 3-1-1, Tsushima-Naka, Okayama-shi } 700\end{array}\right)$
}

\begin{abstract}
Composition dependences of the heats of solution of the glasses and crystals in the systems MO- $\mathrm{P}_{2} \mathrm{O}_{5}(\mathrm{M}=\mathrm{Mg}, \mathrm{Ca}, \mathrm{Sr})$ in $3 \mathrm{~N} \mathrm{HNO}_{3}$ aqueous solution have been discussed in terms of the bond dissociation energies of $\mathrm{P}-\mathrm{O}^{\mathrm{b}}$ bridging bonds in the three composition regions; $0<\mathrm{MO}+\mathrm{H}_{2} \mathrm{O} / \mathrm{P}_{2} \mathrm{O}_{5}(=r)<1,1<r<2,2<r<3$. The calculated heats of formation of the $\mathrm{M}\left(\mathrm{PO}_{8}\right)_{2}$ glasses derived the bond energies of bridging and non-bridging $\mathrm{P}-\mathrm{O}$ bonds $\left(E\left(\mathrm{P}-\mathrm{O}^{\mathrm{b}}\right), E\left(\mathrm{P}-\mathrm{O}^{\mathrm{nb}}\right)\right)$ and of $\mathrm{O}-\mathrm{M}-\mathrm{O}$ bonds $(E(\mathrm{OM}))$, based on the assumption $E(\mathrm{P}=\mathrm{O}) /$ $E\left(\mathrm{P}-\mathrm{O}^{\mathrm{b}}\right)=1.75$ and 2.0 .

[Received December 3, 1982]
\end{abstract}

Key-words : Heats of solution, Heats of formation, $\mathrm{MO}-\mathrm{P}_{2} \mathrm{O}_{5}$ systems, Metaphosphate glasses, Bond energy, Polarizing power, $\mathrm{O}-\mathrm{M}$ interaction

\section{1. 緒言}

著者らは前報1), 2) のアルカリリン酸塩 $\left(\mathrm{R}_{2} \mathrm{O}-\mathrm{P}_{2} \mathrm{O}_{5}\right.$, $\mathrm{R}=\mathrm{Li}, \mathrm{Na}, \mathrm{K}$ ) 系ガラスの熱化学的研究において, $3 \mathrm{~N}$ $\mathrm{HNO}_{3}$ 中への溶解熱は $\mathrm{RPO}_{3}$ 組成において 極小值をと ること, これは安定な 2 分岐の $\mathrm{O}=\mathrm{P}(\mathrm{OR}) \mathrm{O}_{2 / 2}$ グルー プが生成するためであることなどを明らかにした．更に $\mathrm{d}-\mathrm{p} \pi$ 結合についての定性的考察から， $\mathrm{P}=\mathrm{O}$ 及び $\mathrm{P}-\mathrm{O}$ 架橋結合エネルギーの $E(\mathrm{P}=\mathrm{O}) / E\left(\mathrm{P}-\mathrm{O}^{\mathrm{b}}\right)$ は比 1.75 2.0 の間にあるとして, $\mathrm{RPO}_{8}$ 組成のガラスの結合エネ ルギー関係を求めている。一方， $\mathrm{MO}-\mathrm{P}_{2} \mathrm{O}_{5}$ 系に関する 予備実験に招いても $\mathrm{R}_{2} \mathrm{O}-\mathrm{P}_{2} \mathrm{O}_{5}$ 采と同様の組成依存性を示している. 本研究 では $\mathrm{MO}-\mathrm{P}_{2} \mathrm{O}_{5}$ 系ガラス及び結晶について熱化学的検討 を行い，またそこで得られた生成熱やそのほかの熱化学 的諸量の文献值から $\mathrm{M}\left(\mathrm{PO}_{3}\right)_{2}$ ガラスの全結合エネルギ 一を計算し, 既報の $\mathrm{MSi}_{2} \mathrm{O}_{5}$ ガラス ${ }^{5)}$ と同様の近似に基 づいて，ガラスを構成する各結合の結合エネルギーを求 めた。. 以下にその概要を報告する.

\section{2. 実験}

\section{1 ガラス試料の作製及び化学分析}

試薬特級の $\mathrm{MgO}, \mathrm{MCO}_{8}(\mathrm{M}=\mathrm{Ca}, \mathrm{Sr})$, 及び $\mathrm{NH}_{4} \mathrm{H}_{2} \mathrm{PO}_{4}$ を所定量ひょう量し, $200^{\circ} \mathrm{C}$ で 12 時間及び $900^{\circ} \sim 1000$ ${ }^{\circ} \mathrm{C}$ で 2 時間前処理したものをバッチとした. ドラフ.ト 中の電気炉にて白金るつぼを使用し，乾燥酸素ガスをバ ブリングさせながら, $1100^{\circ} \sim 1300^{\circ} \mathrm{C}, 2$ 時間の溶融後泠 ステンレス板状に流し出し, 急冷板状試料を得た. あら かじめ定められた徐泠温度にて 30 分間熱処理したもの を以下の化学分析並びに溶解熱測定に用いた. 各ガラス の組成分析 ${ }^{1}$ のうち水分は $\mathrm{ZnO}$ 置換法, $\mathrm{P}_{2} \mathrm{O}_{5}$ はリンモ リブデン酸法により定量を行い，残りを $\mathrm{MO}$ とした.
アルカリ土類金属の種類を問わず約 $1 \mathrm{~mol} \%$ の $\mathrm{H}_{2} \mathrm{O}$ 分 がみられたが，これらはガラス中に㧍いては修飾酸化物 としての働きをするむのと考え，以下組成を表すパラメ 一ターとしては $r=\left(\mathrm{MO}+\mathrm{H}_{2} \mathrm{O}\right) / \mathrm{P}_{2} \mathrm{O}_{5}$ を採用した.

\section{2 結晶試料の作製と $\mathrm{X}$ 線粉末回折による同定}

$\mathrm{M}\left(\mathrm{PO}_{3}\right)_{2}, \mathrm{M}_{2} \mathrm{P}_{2} \mathrm{O}_{7}$ 及び $\mathrm{M}_{8}\left(\mathrm{PO}_{4}\right)_{2}$ 結晶 $(\mathrm{M}=\mathrm{Mg}$ ， Ca) 及び $3 \mathrm{MgO} .2 \mathrm{P}_{2} \mathrm{O}_{5}$ 結晶を作製した. いずれも原料 として試薬特級の $\mathrm{Mg}\left(\mathrm{H}_{2} \mathrm{PO}_{4}\right)_{2} \cdot 3 \mathrm{H}_{2} \mathrm{O}, \mathrm{Mg}_{2} \mathrm{P}_{2} \mathrm{O}_{7}$. $3 \mathrm{H}_{2} \mathrm{O}, \mathrm{Ca}\left(\mathrm{H}_{2} \mathrm{PO}_{4}\right)_{2} \cdot \mathrm{H}_{2} \mathrm{O}, \mathrm{CaHPO}_{4} \cdot 2 \mathrm{H}_{2} \mathrm{O}$ 又はそれらの 混合物を所定温度にて一昼夜熱処理し, 粉砕後再度 2 時 間熱処理して得た. それぞれの粉末 $\mathrm{X}$ 線図形は JCPDS ${ }^{\text {s }}$ の回折線群膤めて良く一致した.

\section{3 溶解熱測定 ${ }^{11}$}

2.2 節で得られたガラス及び結晶試料をべンゼン中で 粉砕並びに $105 \mu \mathrm{m}$ のメッシュでふいるわけし通過した 粉末を溶解熱測定試料とした. 溶解熱は積分器を装着し た東京理工製双子型伝導微少熱量計 TCC-2 型を用い て, $50 \mathrm{~g}$ の $3 \mathrm{~N} \mathrm{HNO}_{3}$ 溶液を溶媒とし $25^{\circ} \mathrm{C}$ にて測定し た. 熱量計はあらかじめ TRIS と $0.1 \mathrm{M} \mathrm{HCl}$ 溶液との 反応熱 で㭘定し，測定值のばらつきは $0.2 \mathrm{kcal} / \mathrm{P}_{2} \mathrm{O}_{5}$ 程度であった. また結晶試料については再熱処理の前後 の測定で有意の差がみられなかった。

\section{3. 結果及び考察}

\section{1 溶解熱の組成依存性}

図 1 は $\mathrm{MO}-\mathrm{P}_{2} \mathrm{O}_{5}$ 系ガラス及び結晶の $3 \mathrm{~N} \mathrm{HNO}_{3}$ 溶 液中一の溶解熱值 $\left(\Delta H_{\mathrm{s}}, \mathrm{P}_{2} \mathrm{O}_{5} 1 \mathrm{~mol}\right.$ 当たりに換算)を組 成比 $r=\left(\mathrm{MO}+\mathrm{H}_{2} \mathrm{O}\right) / \mathrm{P}_{2} \mathrm{O}_{5}$ に対してプロットしたもの である. ガラスは $r=1$ で, 結晶は $r=2$ で屈曲する直 線で表し得る. $0<r<1$ の領域 (I) のガラスの溶解 熱を $r=0$. に外そうすると $\mathrm{Mg}$-及び $\mathrm{Ca}$-ガラスについ 


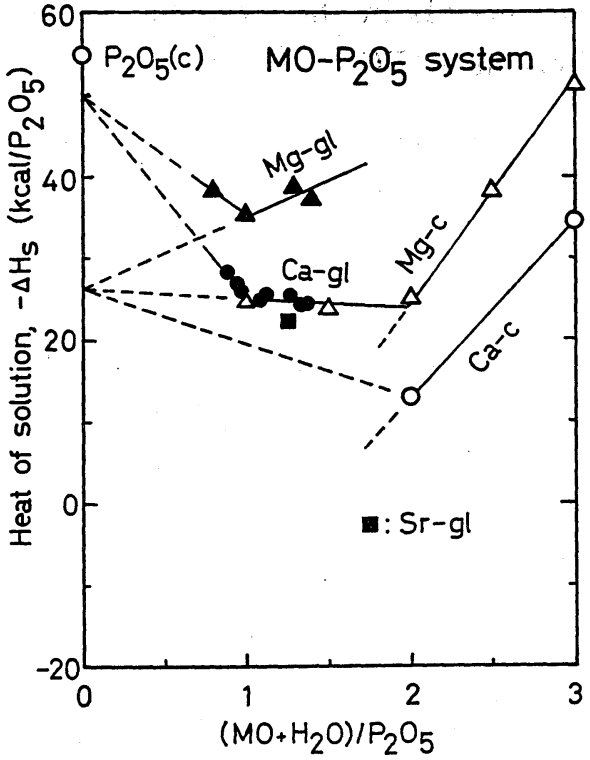

Fig. 1. Heats of solution in $3 \mathrm{~N} \mathrm{HNO}_{3}$ aqueous solution at $25^{\circ} \mathrm{C}$ for the glasses and crystals in the systems $\mathrm{MO}-\mathrm{P}_{2} \mathrm{O}_{5}(\mathrm{M}=\mathrm{Mg}, \mathrm{Ca}, \mathrm{Sr})$ as a function of the molar ratio $\left(\mathrm{MO}+\mathrm{H}_{2} \mathrm{O}\right) / \mathrm{P}_{2} \mathrm{O}_{5}$.

て両者は同一の値 $\left(\Delta \mathrm{H}_{\mathrm{s}}=-50 \mathrm{kcal} / \mathrm{P}_{2} \mathrm{O}_{5}\right)$ を示し，しか もこの值はアルカリリン酸塩における同じ外そう值と一 致している. 更に $1<r<2$ の領域 (II) 加ら $r=0$ に 外そうした場合いずれのガラス及び結晶とも外そう值は $\Delta H_{\mathrm{s}}=-26.5 \mathrm{kcal} / \mathrm{P}_{2} \mathrm{O}_{5}$ を示す. Ba-系結晶は極めて溶 解速度が遅く測定精度が悪かったため実測值としては図 中にプロットしていないが，Mg-結晶や Mg-及び Ca-ガ ラスと同様の挙動をするものと推測できる. $2<r<3$ の領域 (III) から Mg-及び Ca-結晶の測定值を $r=0$ に 外そうすると他の領域における場合と同様二つの外そう 值は互いに一致し, その值は $+30 \mathrm{kcal} / \mathrm{P}_{2} \mathrm{O}_{5}$ であった. このような $r=0$ に外そうした溶解熱值は, 各領域にお ける $\mathrm{P}-\mathrm{O}$ 結合エネルギーをもった仮想的 $\mathrm{P}_{2} \mathrm{O}_{5}$ 結晶の 溶解熱である. したがって，各領域内の P-O 架橋結合 の強さは領域 (I) < 領域 (II) < 領域 (III) の順となる. 例えば領域（II） $(1<r<2)$ における $\mathrm{P}-\mathrm{O}$ 架橋結合 の強さは, $\mathrm{P}_{2} \mathrm{O}_{5}$ (c) の溶解熱值 $\left(-55.0 \mathrm{kcal} / \mathrm{P}_{2} \mathrm{O}_{5}\right)$ とそ の領域からの外そう值 $\left(-26.5 \mathrm{kcal} / \mathrm{P}_{2} \mathrm{O}_{5}\right)$ との差 28.5 $\mathrm{kcal} / \mathrm{P}_{2} \mathrm{O}_{5}$ だけ安定化されていて強いということができ る. ここで用いた $\mathrm{P}_{2} \mathrm{O}_{5}$ (c) の溶解熱值は $\mathrm{H}_{3} \mathrm{PO}_{4}(\mathrm{aq})$, $\mathrm{P}_{2} \mathrm{O}_{5}$ (c) 及び $\mathrm{H}_{2} \mathrm{O}(\mathrm{l})$ の生成熱の文献值 ${ }^{12,8)}$ よりの計算 值であって, 領域 (I) からの $r=0$ への外そう值, 寸 なわち $\mathrm{P}_{2} \mathrm{O}_{5}(\mathrm{gl})$ の溶解熱值よりも $5 \mathrm{kcal} / \mathrm{P}_{2} \mathrm{O}_{5}$ 発熱的 であり，文献にみられるように帛 $\mathrm{P}_{2} \mathrm{O}_{5}$ (c) の生成熱 < $\mathrm{P}_{2} \mathrm{O}_{5}$ (gl) の生成熱, であることを示す. このように $r$ $=1.0,2.0$ における屈曲は, エネルギー的には各領域で の架橋結合の強さが不連続的に変化すること, 構造論的
には MO の添加に伴って徐々に $\mathrm{PO}_{4} 4$ 面体が 3 分岐 $(\mathrm{O}$ $\left.=\mathrm{PO}_{8 / 2}\right)$ から 2 分岐 $\left(\mathrm{O}=\mathrm{P}(\mathrm{OR}) \mathrm{O}_{2 / 2}\right)$ を経て 1 分岐 $(\mathrm{O}=$ $\left.\mathrm{P}(\mathrm{OR})_{2} \mathrm{O}_{1 / 2}\right)$ へと変化していくことに帰着できる.

\section{2 熱的基礎量}

この節では以下の種々の計算に必要な各種の化学種の 生成熱をはじめとする熱的基礎量を示しておく（表 1 ).

これらはすべて JANAF Thermochemical Tables ${ }^{8)}$ 及

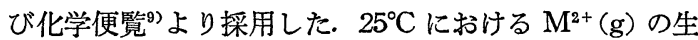
成熱は次のような熱的・状態的変化に関係している。

$$
\begin{aligned}
\mathrm{M}(\mathrm{c}, 0 \mathrm{~K}) \rightarrow \mathrm{M}^{2+}(\mathrm{g}, 0 \mathrm{~K})+2 \mathrm{e}(\mathrm{g}, 0 \mathrm{~K}) \\
\rightarrow \mathrm{M}(\mathrm{c}, 298 \mathrm{~K}) \\
\rightarrow \mathrm{M}^{2+}(\mathrm{g}, 298 \mathrm{~K})+2 \mathrm{e}(\mathrm{g}, 298 \mathrm{~K})
\end{aligned}
$$

したがって，

$$
\begin{aligned}
\Delta H & \left(\mathrm{M}^{2+}(\mathrm{g}), 298 \mathrm{~K}\right) \\
= & H\left(\mathrm{M}^{2+}(\mathrm{g}), 298 \mathrm{~K}\right)+2 H(\mathrm{e}(\mathrm{g}), 298 \mathrm{~K}) \\
& -H(\mathrm{M}(\mathrm{c}), 298 \mathrm{~K})
\end{aligned}
$$

である. 電子ガス $(\mathrm{e}(\mathrm{g}))$ の生成熱は定義によって常に $\Delta H_{\mathrm{f}}(\mathrm{e}(\mathrm{g}))=0$ であるが, $\mathrm{M}^{2+}+2 \mathrm{e}$ なる気体を $0 \mathrm{~K}$ から $298 \mathrm{~K}$ にするためには $5 / 2 R \times 3 \times 298=4.4 \mathrm{kcal} / \mathrm{mol}(R$ : 気体定数）の熱が必要である. 結局，

$$
\begin{aligned}
\Delta H_{\mathrm{f}} & \left(\mathrm{M}^{2+}(\mathrm{g}), 298 \mathrm{~K}\right) \\
= & \Delta H_{\mathrm{f}}\left(\mathrm{M}^{2+}(\mathrm{g}), 0 \mathrm{~K}+4.4-(H(\mathrm{M}(\mathrm{c}), 298 \mathrm{~K})\right. \\
& -H(\mathrm{M}(\mathrm{c}), 0 \mathrm{~K}))
\end{aligned}
$$

となり，これにしたがって著者らが算出した值を表 1 に 示した.

Table 1. Heats of formation data for several chemical species.

\begin{tabular}{lrllll} 
Heat of formation & ref. & \multicolumn{2}{l}{ Heat of formation } & ref. \\
\hline MgO(c) & -143.8 & 8 & $\mathrm{Mg}(\mathrm{g})$ & 35.3 & 8 \\
$\mathrm{CaO}(\mathrm{c})$ & -151.8 & 8 & $\mathrm{Ca}(\mathrm{g})$ & 42.8 & 8 \\
$\mathrm{SrO}(\mathrm{c})$ & -141.5 & 8 & $\mathrm{Sr}(\mathrm{g})$ & 39.2 & 8 \\
$\mathrm{O}(\mathrm{g})$ & 59.6 & 8 & $\mathrm{P}(\mathrm{g})$ & 75.6 & 8 \\
$\mathrm{P}_{2} \mathrm{O}_{5}(\mathrm{c})$ & -359.7 & 8 & $\mathrm{Mg}^{2+}(\mathrm{g})$ & 561.1 & 5 \\
$\mathrm{Ca}^{2+}(\mathrm{g})$ & 460.4 & 5 & $\mathrm{Sr}^{2+}(\mathrm{g})$ & 427.7 & 5 \\
\hline
\end{tabular}

* $\mathrm{kcal} / \mathrm{mol}$

\section{$3.3 \mathrm{M}\left(\mathrm{PO}_{3}\right)_{2}(\mathrm{M}=\mathrm{Mg}, \mathrm{Ca}, \mathrm{Sr})$ ガラスの生成熱}

$\mathrm{M}\left(\mathrm{PO}_{3}\right)_{2}$ 結晶の生成熱が未知であり，またその溶解 熱が測定できていないので, 通常の方法によってガラス の生成熱を得ることはできない. そこで本研究では以下 の方法 ${ }^{1), 2)}$ によって $\mathrm{RPO}_{3}$ ガラスと類似の $\mathrm{M}\left(\mathrm{PO}_{3}\right)_{2}$ ガ ラスの生成熱を求めた. まず $\mathrm{MO}(\mathrm{c}), \mathrm{P}_{2} \mathrm{O}_{5}$ (c) の生成反 応及び $3 \mathrm{~N} \mathrm{HNO}_{3}$ 溶液中への溶解反応より

$$
\begin{aligned}
\mathrm{M}(\mathrm{c}) & +\frac{1}{2} \mathrm{O}_{2}(\mathrm{~g})+2 \mathrm{H}^{+}(\mathrm{sol}) \\
\rightarrow & \mathrm{M}^{2+}(\mathrm{sol})+\mathrm{H}_{2} \mathrm{O}(\mathrm{l})+H_{\mathrm{f}}(\mathrm{MO}(\mathrm{c})) \\
& +h_{\mathrm{s}}(\mathrm{MO}(\mathrm{c}))
\end{aligned}
$$

及び

$$
2 \mathrm{P}(\mathrm{c})+\frac{5}{2} \mathrm{O}_{2}(\mathrm{~g})+3 \mathrm{H}_{2} \mathrm{O}(\mathrm{l})
$$




$$
\rightarrow 2 \mathrm{H}_{8} \mathrm{PO}_{4}(\mathrm{sol})+H_{\mathrm{f}}\left(\mathrm{P}_{2} \mathrm{O}_{5}(\mathrm{c})\right)+h_{\mathrm{s}}\left(\mathrm{P}_{2} \mathrm{O}_{5}(\mathrm{c})\right)
$$

一方, $\mathrm{M}\left(\mathrm{PO}_{8}\right)_{2}$ ガラスの生成反応及び溶解反応から は

$$
\begin{aligned}
\mathrm{M}(\mathrm{c}) & +2 \mathrm{P}(\mathrm{c})+3 \mathrm{O}_{2}(\mathrm{~g})+2 \mathrm{H}^{+}(\mathrm{sol})+2 \mathrm{H}_{2} \mathrm{O}(\mathrm{l}) \\
\rightarrow & \mathrm{M}^{2+}(\mathrm{sol})+2 \mathrm{H}_{8} \mathrm{PO}_{4}(\mathrm{sol}) \\
& +H_{\mathrm{f}}(\mathrm{M}-\mathrm{gl})+h_{\mathrm{s}}(\mathrm{M}-\mathrm{gl})
\end{aligned}
$$

が得られる.ここに $H_{\mathrm{f}}, h_{\mathrm{s}}$ は生成及び溶解反応におけ る反応熱であり, 化学種の状態のうち, c, l, g, sol はそ れぞれ結晶, 液体, 気体, 及び溶媒和の状態であること を示し, $\mathrm{M}$-gl は $\mathrm{M}\left(\mathrm{PO}_{3}\right)_{2}$ ガラスを表している. (1) 式，(2) 式の反応後の溶液同士の混合エンタルピーが無 視できるなら，混合後の溶液は (3) 式の反応後の溶液と 等価である. したがって，M-gl の生成熱 $\Delta H_{\mathrm{f}}(\mathrm{M}-\mathrm{gl})$ $\left(=-H_{\mathrm{f}}(\mathrm{M}-\mathrm{gl})\right)$ は

$$
\begin{aligned}
\Delta H_{\mathrm{f}}(\mathrm{M} \cdot \mathrm{gl})= & h_{\mathrm{s}}(\mathrm{M} \cdot \mathrm{gl})-H_{\mathrm{f}}(\mathrm{MO}(\mathrm{c})) \\
& -H_{\mathrm{f}}\left(\mathrm{P}_{2} \mathrm{O}_{5}(\mathrm{c})\right)-h_{\mathrm{s}}(\mathrm{MO}(\mathrm{c})) \\
& -h_{\mathrm{s}}\left(\mathrm{P}_{2} \mathrm{O}_{5}(\mathrm{c})\right)
\end{aligned}
$$

で与えられる. 表 2 には実測した $\mathrm{MO}(\mathrm{c})$ 及び $\mathrm{M}-\mathrm{gl}$ の 溶解熱とともに (4) 式で計算した M-gl の生成熱をま とめた.

Table 2. Thermochemical data for $\mathrm{M}\left(\mathrm{PO}_{3}\right)_{2}$ glasses and $\mathrm{MO}$ and $\mathrm{P}_{2} \mathrm{O}_{5}$ crystals.

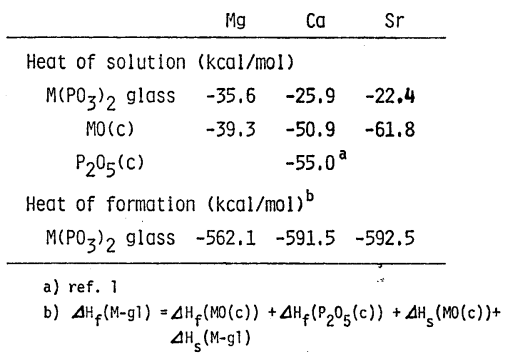

\section{$3.4 \mathrm{M}\left(\mathrm{PO}_{3}\right)_{2}$ ガラスの結合エネルギー関係}

$\mathrm{M}\left(\mathrm{PO}_{3}\right)_{2}$ ガラスの全結合エネルギーは

$\mathrm{M}\left(\mathrm{PO}_{8}\right)_{2}(\mathrm{gl}) \rightarrow \mathrm{M}(\mathrm{g})+2 \mathrm{P}(\mathrm{g})+6 \mathrm{O}(\mathrm{g})-D$

なる解離反応における解離熱 $D$ で定義され, 各化学種 の生成熱の和

$$
\begin{aligned}
D= & -\Delta H_{\mathrm{f}}(\mathrm{M}-\mathrm{gl})+\Delta H_{\mathrm{f}}(\mathrm{M}(\mathrm{g}))+2 \Delta H_{\mathrm{f}}(\mathrm{P}(\mathrm{g})) \\
& +6 \Delta H_{\mathrm{f}}(\mathrm{O}(\mathrm{g}))
\end{aligned}
$$

で与えられる. $\mathrm{M}\left(\mathrm{PO}_{8}\right)_{2}$ ガラスは $\mathrm{P}=\mathrm{O}$ 二重結合, $\mathrm{P}$ $\mathrm{O}^{\mathrm{nb}}$ 非架橋結合がそれぞれ 2 本, $\mathrm{P}-\mathrm{O}^{\mathrm{b}}$ 架橋結合が 4 本 及び一組の O-M-O 結合から構成されている. したがっ て，(6) 式の結合エネルギー関倸

$$
\begin{aligned}
& D=2 E(\mathrm{P}=\mathrm{O})+4 E\left(\mathrm{P}-\mathrm{O}^{\mathrm{b}}\right)+2 E\left(\mathrm{P}-\mathrm{O}^{\mathrm{nb}}\right)+E(\mathrm{OM}) \\
& E(\mathrm{P}-\mathrm{OM})=E\left(\mathrm{P}-\mathrm{O}^{\mathrm{nb}}\right)+\frac{1}{2} E(\mathrm{OM})
\end{aligned}
$$

が成立する. 一方ガラス 構造中からリン酸アニオン
$2 \mathrm{PO}_{3}{ }^{-}(\mathrm{gl})$ を残したまま $\mathrm{M}^{2+}(\mathrm{g})$ を取り出すに要する エネルギーを $E^{\prime}(\mathrm{OM})$.とすれば，

$$
\mathrm{M}\left(\mathrm{PO}_{8}\right)_{2}(\mathrm{gl}) \rightarrow \mathrm{M}^{2+}(\mathrm{g})+2 \mathrm{PO}_{3}^{-}(\mathrm{gl})-E^{\prime}(\mathrm{OM})
$$

$\mathrm{M}^{2+}(\mathrm{g})$ 及びリン酸アニオンの生成反応はそれぞれ

$$
\begin{aligned}
& \mathrm{M}(\mathrm{c}) \rightarrow \mathrm{M}^{2+}(\mathrm{g})+2 \mathrm{e}^{-}-H_{\mathrm{f}}\left(\mathrm{M}^{2+}(\mathrm{g})\right) \\
& 2 \mathrm{P}(\mathrm{c})+3 \mathrm{O}_{2}(\mathrm{~g})+2 \mathrm{e}^{-} \rightarrow 2 \mathrm{PO}^{-}(\mathrm{gl})+H
\end{aligned}
$$

と表しうる. これらの 3 式から

$$
\begin{aligned}
& \mathrm{M}(\mathrm{c})+2 \mathrm{P}(\mathrm{c})+3 \mathrm{O}_{2}(\mathrm{~g}) \\
& \quad \rightarrow \mathrm{M}\left(\mathrm{PO}_{3}\right)_{2}(\mathrm{gl})+E^{\prime}(\mathrm{OM})-H_{\mathrm{f}}\left(\mathrm{M}^{2+}(\mathrm{g})\right)+H
\end{aligned}
$$

が得られる.これは $\mathrm{M}\left(\mathrm{PO}_{3}\right)_{2}$ ガラスの生成反応である から

$$
E^{\prime}(\mathrm{OM})=H_{\mathrm{f}}(\mathrm{M} \cdot \mathrm{gl})+H_{\mathrm{f}}\left(\mathrm{M}^{2+}(\mathrm{g})\right)-H
$$

なる関係式が得られる. $\mathrm{M}=\mathrm{Mg}, \mathrm{Ca}, \mathrm{Sr}$ について (7) 式が成立するが， 3 種の $E^{\prime}(\mathrm{OM})$ 及びリン酸アニオン の生成熱 $H$ が未知であるため，(7) 式を連立させた方 “程式は一義的には解けない。 ここでは前報》の $\mathrm{MSi}_{2} \mathrm{O}_{5}$ ガラスにおけると同様， $\mathrm{MO}$ 結晶の格子エネルギー $U$ を簡略化された Born-Mayer 型の方程式

$$
U=z^{2} e^{2} A \cdot N_{\mathrm{A}} \cdot 1 / d(\mathrm{M}-\mathrm{O}) \cdot\left(1-\rho_{\mathrm{M}} / d(\mathrm{M}-\mathrm{O})\right)
$$

で表したときの反発力項のパラメーター $\rho_{\mathrm{M}}$ がガラス中 の $\mathrm{M}-\mathrm{O}$ 相互作用にも適用できるものとする $\left(\rho_{\mathrm{Ca}}=0.36\right.$ $\AA, \rho_{\mathrm{Sr}}=0.35 \AA$ ) . また $E^{\prime}(\mathrm{OCa})$ 及び $E^{\prime}(\mathrm{OSr})$ につい ては同一のパラメーター $A$ によって

$$
\begin{gathered}
E^{\prime}(\mathrm{OM})=A / d(\mathrm{M}-\mathrm{O}) \cdot\left(1-\rho_{\mathrm{M}} / d(\mathrm{M}-\mathrm{O})\right) \\
(\mathrm{M}=\mathrm{Ca}, \mathrm{Sr}) \quad(8)
\end{gathered}
$$

なる関係が成立するものとする。ここに $d(\mathrm{M}-\mathrm{O})$ はガ ラス中に㧍ける平均の $\mathrm{M}-\mathrm{O}$ 距離である。これらのパラ メーターを用いれば，(7) 式，(8) 式に従って $E^{\prime}(\mathrm{OM})$ は計算できる. 更に表 2 の生成熱值からガラス中の全結 合エネルギー $D$ を求めれば，ガラスを構成する各結合 の結合エネルギーが計算より得られる. アルカリメタリ ン酸塩ガラスに扔いては $3 \mathrm{~d}-2 \mathrm{p} \pi$ 結合に関する定性的 検討から $1.75<E(\mathrm{P}=\mathrm{O}) / E\left(\mathrm{P}-\mathrm{O}^{\mathrm{b}}\right)<2$ と考えた ${ }^{2)}$. 本 研究でも, その比が 1.75 及び 2 の場合について計算し, 後者の結果は括弧内に示した. $E\left(\mathrm{P}-\mathrm{O}^{\mathrm{b}}\right)$ については溶解 熱測定の結果より，28.5 kcal $/ \mathrm{P}_{2} \mathrm{O}_{5}$ の安定化エネルギー が認められたため，

$$
\begin{aligned}
E\left(\mathrm{P}-\mathrm{O}^{\mathrm{b}}\right) & =\left(D\left(\mathrm{P}_{2} \mathrm{O}_{5}(\mathrm{c})\right)+28.5\right) / 9.5(10) \\
& =88.1(83.7) \quad(\mathrm{kcal} / \mathrm{mol})
\end{aligned}
$$

である. 更に $E^{\prime}(\mathrm{OM})$ はその定義から (6) 式における $E(\mathrm{OM})$ よりは $\mathrm{M}$ のイオン化ポテンシャル $I(\mathrm{M})$ だけ 大きく, $2 H_{\mathrm{a}}$ ( $H_{\mathrm{a}}$ は非架橋酸素の電子親和力)だけ小さ い值となっている

$$
E^{\prime}(\mathrm{OM})=E(\mathrm{OM})+I(\mathrm{M})-2 H_{\mathrm{a}}
$$

であり, $H_{\mathrm{a}}$ は

$$
\mathrm{O}_{2 / 2}(\mathrm{O}=) \mathrm{P}-\mathrm{O}(\mathrm{gl})+\mathrm{e} \rightarrow \mathrm{O}_{2 / 2}(\mathrm{O}=) \mathrm{P}-\mathrm{O}^{-}(\mathrm{gl})
$$

$+H_{\mathrm{a}}$

なる反応熱で定義される．これまでは12,2) $H_{\mathrm{a}}$ を無視 
Table 3. Bond energy relations in $\mathrm{M}\left(\mathrm{PO}_{8}\right)_{2}$ glasses $(\mathrm{kcal} / \mathrm{mol})$.

\begin{tabular}{ccccccc} 
Glass & $D^{a}$ & $E\left(P-0^{b}\right)$ & $E(P-O M)$ & $E^{\prime}(O M)$ & $E(O M)^{b}$ & $E\left(P-0^{n b}\right)^{b}$ \\
\hline$M g\left(P_{3}\right)_{2}$ & 1106 & $\vdots$ & $223(218)$ & 611 & 155 & \\
$\mathrm{Ca}\left(\mathrm{PO}_{3}\right)_{2}$ & 1143 & 88 & $241(237)$ & 540 & 192 & 145 \\
$\mathrm{Sr}\left(\mathrm{PO}_{3}\right)_{2}$ & 1144 & $(84)$ & $241(237)$ & 511 & 192 & $(141)$ \\
\hline
\end{tabular}

$E\left(p-0^{b}\right), E(P-O M)$ and $E\left(P-0^{n b}\right)$ have been calculated on assuming the ratio $E(p=0) / E(P-0 b)=1.75$ and 2 . The values for the latter case are shown in the parenthesis.

a] $D=4 E\left(P-0^{b}\right)+2 E(P=0)+2 E\left(P-0^{n b}\right)+E(O M)$

b] The electron affinity of the non-bridging oxygen $\mathrm{Ha}$ is assumed to be $35 \mathrm{kcal} / \mathrm{mol}$. Ha is defined as the heat of reaction; $O_{2 / 2}(0=) P-0$ $+\mathrm{e} \rightarrow 0_{2 / 2}(\mathrm{O}=) \mathrm{P}-\mathrm{O}^{-}+\mathrm{Ha}$.

$E(O M)=E^{\prime}(O M)-I(M)+2 \mathrm{Ha} ; I(M)=$ the ionization potential of $M$.

（ $H_{\mathrm{a}}=0$ と仮定）してきたが，ここでは酸素原子の電子 親和力に等しいと仮定して計算した $\left(H_{\mathrm{a}}=35 \mathrm{kcal} /\right.$ $\left.\mathrm{mol}^{8)}\right)$. なお,

$$
I(\mathrm{M})=\Delta H_{\mathrm{f}}\left(\mathrm{M}^{2+}(\mathrm{g})\right)-\Delta H_{\mathrm{f}}(\mathrm{M}(\mathrm{g}))
$$

であり,

$$
E\left(\mathrm{P}-\mathrm{O}^{\mathrm{nb}}\right)=E(\mathrm{P}-\mathrm{OM})-E(\mathrm{OM}) / 2
$$

で得られる. 以上の結果を表 3 に示した.

$E\left(\mathrm{P}-\mathrm{O}^{\mathrm{nb}}\right) / E\left(\mathrm{P}-\mathrm{O}^{\mathrm{b}}\right)$ の比は $E(\mathrm{P}=\mathrm{O}) / E\left(\mathrm{P}-\mathrm{O}^{\mathrm{b}}\right)=1.75$ 及び 2 としたいずれの場合もそれぞれ $1.6,1.7$ となっ て抒り，P-O $\mathrm{O}^{\mathrm{nb}}$ は $\mathrm{P}-\mathrm{O}^{\mathrm{b}}$ に比べて極めて強い結合であ ることを示すが，隣接する $\mathrm{P}=\mathrm{O}$ 二重結合と $3 \mathrm{~d}-2 \mathrm{p} \pi$ 結合を通じて共鳴の状態にあり，エネルギー的には $E$ $(\mathrm{P}=\mathrm{O})$ とここでの $E\left(\mathrm{P}-\mathrm{O}^{\mathrm{nb}}\right)$ との平均をとるむのと考 えられる。

$E^{\prime}(\mathrm{OM})$ と比較するために距離 $d(\mathrm{M}-\mathrm{O})$ だけ離れた $\mathrm{M}^{2+}$ - $\mathrm{O}^{2-}$ イオンペア間に㗢くクーロン相互作用エネル ギー $E_{\mathrm{c}}(\mathrm{OM})$ を計算してみると，

$$
E_{\mathrm{c}}=332.1 \cdot \mathrm{z}^{2} / d(\mathrm{M}-\mathrm{O}) \quad\left(\mathrm{kcal} / \mathrm{mol}, \mathrm{z}^{2}=4\right)
$$

であるから $\mathrm{M}=\mathrm{Mg}, \mathrm{Ca}, \mathrm{Sr}$ についてそれぞれ $627 \mathrm{kcal} /$ $\mathrm{mol}, 538 \mathrm{kcal} / \mathrm{mol}, 501 \mathrm{kcal} / \mathrm{mol}$ である ${ }^{5)}$.ここで求め た $E^{\prime}(\mathrm{OM})$ との比 $E^{\prime}(\mathrm{OM}) / E_{\mathrm{c}}$ はガラス中の $\mathrm{M}^{2+}$ イ オンに関する見掛けのマーデルング定数で，それらは $\mathrm{M}=\mathrm{Mg}, \mathrm{Ca}, \mathrm{Sr}$ について 0.97, 1.00, 1.02 である. したがって $\mathrm{M}\left(\mathrm{PO}_{8}\right)_{2}$ ガラス中の $\mathrm{M}^{2+}$ イオンは，全体 としては $\mathrm{M}^{2+}$ と $\mathrm{O}^{2-}$ とのクーロン相互作用に等しい結 合力を示し, 更にその静電的作用は隣接する酸素によっ てほぼ完全にしゃへいされているといえる． $\mathrm{MSi}_{2} \mathrm{O}_{5}$ ガ ラスでは $\mathrm{M}$ の見掛けのマーデルング定数は $\mathrm{M}=\mathrm{Mg}$ ， $\mathrm{Ca}, \mathrm{Sr}, \mathrm{Ba}$ についてそれぞれ 1.08, 1.16, 1.18, 1.18 であるから ${ }^{5)}$ ，その静電的しゃへいの程度は $\mathrm{M}\left(\mathrm{PO}_{3}\right)_{2}$ ガラスの方がより完全であることが分る. また $E(\mathrm{OM})$ の大きさの順 $(\mathrm{Mg}<\mathrm{Ca} \approx \mathrm{Sr})$ については非架橋酸素の 分極を考慮すれば，ケイ酸塩系 ${ }^{5}$ と同様に定性的ではあ るが説明可能である.

\section{4. 総 括}

アルカリ土類リン酸塩系ガラス及び結晶の $3 \mathrm{~N} \mathrm{HNO}_{3}$ 溶液中への溶解熱を $25^{\circ} \mathrm{C}$ にて測定しその組成比 $r=$
$\left(\mathrm{MO}+\mathrm{H}_{2} \mathrm{O}\right) / \mathrm{P}_{2} \mathrm{O}_{5}$ に対する依存性を調べた. その結果， 溶解熱は， $r=1,2$ で屈曲する直線で表され，各領域 ((I) : $0<r<1$; (II) : $1<r<2$; (III) $: 2<r<3$ ) から $r=0$ 一外そうしたそれぞれの值は $\mathrm{M}$ の種やガラ スと結晶とを問わず一致した．それらの外そう值は各領 域における強さの $\mathrm{P}-\mathrm{O}$ 架橋結合により構成される仮想 的な $\mathrm{P}_{2} \mathrm{O}_{5}$ ガラスの溶解熱であり, $\mathrm{P}_{2} \mathrm{O}_{5}$ (c) のそれとの 差は $\mathrm{MO}$ の添加により 3 分岐の $\mathrm{PO}_{4}$ から 2 分岐, 1 分 岐へと変化する際の安定化エネルギーである. 別途測定 した $\mathrm{MO}(\mathrm{c})$ の溶解熱及び生成熱の文献值 ${ }^{8), 9}$ から各 $\mathrm{M}\left(\mathrm{PO}_{3}\right)_{2}$ ガラスの生成熱は $\mathrm{M}=\mathrm{Mg}, \mathrm{Ca}, \mathrm{Sr}$ について $-562.1 \mathrm{kcal} / \mathrm{mol},-591.5 \mathrm{kcal} / \mathrm{mol}, \quad-592.5 \mathrm{kcal} / \mathrm{mol}$ であった.

$\mathrm{M}\left(\mathrm{PO}_{3}\right)_{2}$ ガラスを原子気体状態にまで分解するのに 必要な全結合エネルギーを各結合に割り振った．計算は $E(\mathrm{P}=\mathrm{O}) / E\left(\mathrm{P}-\mathrm{O}^{\mathrm{b}}\right)=1.75$ 及び 2 の場合について行い, 後者の結果を括弧内に示した. その結果，いずれの $\mathrm{M}$ $\left(\mathrm{PO}_{3}\right)_{2}$ ガラスに扔いても架橋結合エネルギー $E\left(\mathrm{P}-\mathrm{O}^{\mathrm{b}}\right)$ は 88(84), 非架橋結合については，非架橋酸素の電子 親和力 $H_{\mathrm{a}}=35 \mathrm{kcal} / \mathrm{mol}$ と仮定したとき，145(141) $\mathrm{kcal} / \mathrm{mol}$ であった. またガラス中より $\mathrm{M}^{2+}(\mathrm{g})$ を取り 出すに要するエネルギー $E^{\prime}(\mathrm{OM})$ は $\mathrm{M}=\mathrm{Mg}, \mathrm{Ca}, \mathrm{Sr}$ について $611 \mathrm{kcal} / \mathrm{mol}, 540 \mathrm{kcal} / \mathrm{mol}, 511 \mathrm{kcal} / \mathrm{mol}$ で あり， $\mathrm{M}^{2+}-\mathrm{O}^{2-}$ イオンペア間のクーロン相互作用のエ ネルギーとほとんど等しく,ガラス中では $\mathrm{M}^{2+}$ イオン は周囲の酸素によって充分静電的にしゃへいされること が分った.

謝辞 本研究遂行に当たり熱心に協力された元本学学生 福原伸敏君並びに藤原 誠君に感謝致します。

\section{文献}

1）高橋克明, 尾坂明義, 林 聡, 窯協, 90, 8-13 (1982).

2）高橋克明，尾坂明義，林 聡，窯協，90, 51-55 (1982).

3) 高橋克明, 尾坂明義, 日本化学会第 44 秋季年会予稿集, 岡山 (1981).

4) 高橋克明, 尾坂明義, 林 聡, 福原伸敏, 第 3 回無機 リン化学討論会講演予稿集, 東京 (1981).

5）高橋克明, 尾坂明義, 窯協, 91, 358-63 (1983).

6) "Powder Diffraction File", JCPDS International Center for Diffraction Data. $\mathrm{Mg}\left(\mathrm{PO}_{3}\right)_{2}: 27-1273, \mathrm{Mg}_{2} \mathrm{P}_{2} \mathrm{O}_{7}$ : $8-38, \quad \mathrm{Mg}_{3}\left(\mathrm{PO}_{4}\right)_{2}: 25-1373, \beta-\mathrm{Ca}\left(\mathrm{PO}_{8}\right)_{2}: 11-39, \beta-$ $\mathrm{Ca}_{2} \mathrm{P}_{2} \mathrm{O}_{7}: 11-177, \alpha-\mathrm{Ca}_{3}\left(\mathrm{PO}_{4}\right)_{2}: 9-348$.

7) J.O. Hill, G. Öjelund and I. Wadsö, J. Chem. Thermodynamics, 1, 111-16 (1969).

8) "JANAF Thermochemical Tables", US Department of Commerce, 2nd ed. (1970); Supplements : 1974, 1975 and 1978.

9）“化学便覧”, 基礎編 II, 第 8 章, 日本化学会編, 丸善, 東 京 (1981).

10) R.D. Shannon and C.T. Prewitt, Acta Cryst., B 25, 925-46 (1969). 